\title{
Levels and associations among self-esteem, fertility distress, coping, and reaction to potentially being a genetic carrier in women with diminished ovarian reserve
}

\author{
Ceylan Cizmeli, M.A. ${ }^{a}$, Marci Lobel, Ph.D. ${ }^{a}$, Jason Franasiak, M.D. ${ }^{b}$, and Lisa M. Pastore, \\ Ph.D. ${ }^{\mathrm{C}}$ \\ aDepartment of Psychology, Stony Brook University, Stony Brook, New York \\ bepartment of Obstetrics and Gynecology, School of Medicine, University of North Carolina, \\ Chapel Hill, North Carolina \\ 'Department of Obstetrics and Gynecology, School of Medicine, University of Virginia, \\ Charlottesville, Virginia
}

\section{Abstract}

Objective-To measure the level of distress and its relationship with other psychologic factors in women with diminished ovarian reserve (DOR) who participated in a fragile X genetics study.

Design—Longitudinal data analyzed with structural equation modeling.

Setting-Four U.S. private and academic fertility centers.

Patient(s)—Sixty-two infertile patients with DOR.

Intervention(s)-None.

Main Outcome Measure(s)-Fertility Problem Inventory, Coping Scale for Infertile Couples, Rosenberg Self-Esteem, Health Orientation Scale.

Result(s)—Nineteen percent had low fertility distress, $56 \%$ had average fertility distress, and $24 \%$ had high fertility distress. Thirty-six percent self-reported a "favorable" or "very favorable" emotional response to potentially being a fragile X carrier (termed "emotions"), 53\% were "ambivalent," and $11 \%$ had an unfavorable reaction. Three months after learning that they were not a carrier, these percentages were $91 \%, 9 \%$, and $0 \%$, respectively. Emotions at this second time point were significantly more positive than at pretesting. At baseline, higher self-esteem was a significant predictor of reduced fertility distress both directly and indirectly through emotions. Fertility distress was not associated with coping. Self-esteem, fertility distress, pretesting emotions, and coping were unrelated to posttesting emotions.

Conclusion(s)-The potential of having an explanation for one's DOR condition may have a beneficial impact on women's psychologic states during the process of genetic testing, and this appeared to be especially true for women with higher self-esteem. Psychologic interventions

Copyright $\odot 2013$ American Society for Reproductive Medicine, Published by Elsevier Inc.

Reprint requests: Lisa M. Pastore, Ph.D., Dept. of OB/GYN, P.O. Box 800712, Charlottesville, Virginia 22908-0712 (lpastore@virginia.edu). .

C.C. has nothing to disclose. M.L. has nothing to disclose. J.F. has nothing to disclose. L.M.P. has nothing to disclose.

Discuss: You can discuss this article with its authors and with other ASRM members at http://fertstertforum.com/cizmelic-fertilitygenetic-counseling-diminished-ovarian-reserve/ 
targeted to women with low self-esteem may reduce distress and improve reactions to genetic testing.

\section{Keywords}

Infertility; female infertility; structural equation modeling; diminished ovarian reserve; fragile X; distress; genetic counseling

Infertility affects $\sim 9 \%$ of couples worldwide (1), including $\sim 72$ million women aged $20-44$ years (1). A reduction in oocyte quantity and quality with advanced age is a normal physiologic occurrence termed "diminished ovarian reserve" (DOR) (2). DOR is diagnosed in $\sim 10 \%$ of women seeking fertility assistance $(3,4)$. Although the average age of female infertility due to normal ovarian aging is the mid-forties, some women experience DOR much earlier and thus become prematurely infertile. Women with DOR have regular menstrual periods and their diagnosis is generally a surprise because they believe they are fertile if they menstruate regularly (5). These women sometimes project the notion of having "old eggs" onto themselves, resulting in perceptions of the self as being aged and unhealthy (5).

The fragile $\mathrm{X}$ mental retardation 1 (FMR1) gene is associated with an increased risk of premature ovarian failure (POF), and the American College of Obstetricians and Gynecologists recommends FMR1 screening in women with elevated FSH before age 40 without known cause (6). FMR1 is a trinucleotide gene measured by the count of cytosineguanine-guanine (CGG) repeats. An expansion of $>200$ CGG repeats causes fragile X syndrome, the most common heritable form of mental retardation in male individuals. Male and female individuals with 55-199 CGG repeats are termed "premutation carriers." There is evidence that the premutation carriers $(7,8)$, and potentially women with high normal $(9$, 10) or intermediate $(8,11)$ levels of repeats $(35-44$ and 45-54 CGG repeats, respectively), have an increased risk of POF and/or DOR.

Involuntary childlessness can cause significant distress for couples, although some adapt well to this stressful life event. Qualitative studies have analyzed the experience of infertility within its social context. Several themes have been described: 1) unanticipated life-course disruption $(12,13) ; 2)$ sense of lost time $(5,14) ; 3)$ sense of worthlessness, inadequacy, and lack of control $(15,16)$; 4) social isolation (17); and 5) hope-disappointment cycles (18). In addition to these themes, Dunkel-Schetter and Lobel (19) reported that the following emotional responses to infertility were common according to the literature: grief and depression, anger, guilt, shock/denial, and anxiety. Similar emotional responses have been reported in reaction to a diagnosis of POF (20).

Little is known about the psychologic condition of women with specific infertility diagnoses such as DOR who are facing the prospect of a specific genetic diagnosis. Although publications have formally examined fertility distress in women with infertility diagnoses (21-31), we are unaware of any report examining fertility distress in a preconception genetic testing setting. Other psychologic constructs assessed previously are anxiety, depression, resilience, coping, life events, social support, quality of life, marital adjustment, stigma, disclosure, and overall stress. Pertinent to our study is evidence linking infertility distress with coping $(23,25-27)$ (although unsupported by others [29]) and self-esteem (32). Mental health has been reported to affect the success of fertility treatment $(33,34)$.

The purpose of the present report was to examine levels of and hypothesized associations among fertility distress, coping, self-esteem, and emotional reactions to potentially being a fragile X carrier in women diagnosed with DOR. To our knowledge, this is the first report to 
investigate self-esteem and emotional reactions to potentially being a genetic carrier of a disorder in relation to fertility distress. The specific hypotheses are listed below and illustrated in Supplemental Figure 1 (available online at www.fertstert.org):

- Higher self-esteem is associated with lower fertility distress, as is consistent with related evidence on self-esteem and infertility (19).

- Higher self-esteem predicts a more positive emotional reaction toward potentially being a fragile $\mathrm{X}$ premutation carrier. Positive self-views promote adjustment to stressful situations and negative feedback $(35,36)$. Women's perspective about a potential explanation for their infertility is likely to contribute to the degree of distress they are experiencing. Consequently, having a more positive emotional reaction toward potentially being a fragile $\mathrm{X}$ carrier is hypothesized to predict lower fertility distress. Conversely, women who have a more negative emotional reaction to the possibility of being a fragile $\mathrm{X}$ carrier are hypothesized to experience greater fertility distress.

- Coping is activated by a greater degree of distress, as is consistent with well accepted stress and coping theories (37).

\section{MATERIALS AND METHODS}

The sample consisted of women diagnosed with DOR who enrolled through reproductive endocrinology and infertility clinics. A description of the underlying study (prevalence study of fragile X trinucleotide repeat levels in women with DOR) appears elsewhere (9). Briefly, eligibility requirements included: diagnosis of DOR (elevated FSH or few antral follicles or low antimüllerian hormone levels), age at DOR diagnosis $\leq 42$ years, and regular menstrual cycles for the preceding 6 months. Criteria for exclusion were: known cause of elevated FSH for one's age unrelated to fragile X (e.g., surgical removal of one or both ovaries, chemotherapy or radiation therapy, Turner syndrome, autoimmune disease), and a family history of fragile $\mathrm{X}$ syndrome or premutation.

Participants were enrolled from March 2005 to September 2011 from academic reproductive endocrinology and infertility clinics in California (40\%) and North Carolina (19\%) and private fertility practices in Virginia (34\%) and North Carolina (7\%). The study was approved by the Human Ethics Boards at all academic sites (University of Virginia Institutional Review Board no. 11448). Recruitment consisted of targeted mailings, flyers in waiting rooms, and physician referrals. The recruitment methods varied by site and over time.

After providing informed consent, women provided a single blood sample for the genetics analysis (reported previously [9]) and received pretest genetic counseling by a certified genetic counselor. Study materials, biologic samples, and results were deidentified for confidentiality purposes. Psychologic instruments were self-administered at a study visit after the genetic counseling and blood draw. Questionnaires and/or medical record reviews were the source of all demographic, reproductive, and family medical history variables. Follow-up data were obtained by a self-administered questionnaire 3 months after learning the FMR1 test results. None of the participants was a carrier. Of the 62 women in this report with baseline data, 55 (88.7\%) completed the follow-up questionnaire. One participant did not want to learn her results and per protocol was not requested to complete a follow-up questionnaire; six women declined to complete the follow-up questionnaire. 


\section{Measures}

1. Self-esteem-The Rosenberg Self-Esteem Scale (RSE) $(38,39)$ is the most widely used psychometrically robust self-report measure of global self-esteem. This measure has been used with varying response scales; in the present study, the 9-point response scale ranged from "strongly disagree" ( 1 point) to "strongly agree" (9 points). After reversescoring five of the ten items, a total self-esteem score was calculated by summing responses. Higher scores indicate higher self-esteem. The scale was internally consistent: Cronbach $\alpha=0.90$.

2. Fertility distress-The Fertility Problem Inventory (FPI) (21) is a 46-item multidimensional measure that examines fertility-related distress in five domains: social concerns, sexual concerns, relationship concerns, need for parenthood, and rejection of a child-free lifestyle. Items are rated from "strongly disagree" ( 1 point) to "strongly agree" (6 points). After reverse-scoring appropriate items, a global fertility distress score was calculated by summing responses. Higher scores indicate greater fertility distress. The FPI is a highly reliable measure with well established convergent and discriminant validity (21, 23). Although the original version of the instrument exhibited a significant but weak inverse correlation with respondents' level of education, a more recent Greek four-factor version of the instrument was uncorrelated with variables such as education and income (30). The measure had high internal consistency in the present study $(\alpha=0.93)$.

3. Coping strategies-The 15-item Coping Scale for Infertile Couples (CSIC) (40) was developed to be equivalently useful for both women and men when one or both partners are infertile. Participants indicated "how often you use each coping strategy to deal with infertility" (e.g., "read as much as possible from books on infertility") on a 5-point scale from "never" (1 point) to "almost always" (5 points). A global coping score was created by summing responses. The CSIC also measures specific coping strategies: "increasing space," "regaining control," "being the best [one can be]," and "sharing the burden." CSIC scores are correlated with perceived stress (41) and with other coping measures such as the Infertility Questionnaire (42) and the Jalowiec Coping Scale (43). The CSIC had good internal consistency $(\alpha=0.72)$ in the present study.

\section{Emotional reactions to potential identification as a fragile $X$ carrier-The}

Health Orientation Scale (44) was used to measure the psychologic implication of, or emotional reactions to, potential identification as a fragile $\mathrm{X}$ carrier, hereafter termed "potential carrier emotions." Without knowing their genetic test results, participants were asked to describe their current feelings when they considered that they might be a carrier of a fragile X premutation. The measure lists 11 emotional reactions (e.g., "bad vs. good," "angry vs. pleased"). The original measure had a 12th item ("inactive vs. active") that was dropped because of inapplicability to fragile X. Item responses were coded with 1 representing the most negative anchor on the scale (e.g., "bad") and 9 the most positive (e.g., "good"). A total score was calculated by summing responses. Higher scores indicate a more positive emotional reaction toward potentially being a carrier of a fragile $\mathrm{X}$ premutation. Internal consistency of the scale was high: $a=0.89$. In the follow-up questionnaire, women were asked to describe how they feel "about the fact that you are NOT a carrier of a fragile $\mathrm{X}$ premutation" (hereafter referred to as "posttest noncarrier emotions").

\section{Data Analytic Strategy}

Analyses were performed with the use of SPSS 19.0 and AMOS 18.0. Data were first examined for missing values. Nine cases, each with five missing values, were identified and the missing values replaced with the series mean. Data were examined for violations of normality assumptions. Univariate normality was assessed by the Kolmogorov-Smirnov (KS) test. Results indicated that the distribution of self-esteem and posttest noncarrier 
emotions scores deviated significantly from normality $[D(62)=0.20 ; P \leq 01$ for self-esteem; and $D(62)=0.19 ; P<.01$ for posttest noncarrier emotions]; scores were negatively skewed and kurtotic (Zsk $=-1.48 ; Z k u=1.42$ for self-esteem; and $Z s k=-1.25 ; Z k u=0.71$ for posttest noncarrier emotions). Log transformation was performed on the self-esteem and posttest noncarrier emotions scores (45). Transformed scores met the assumption of univariate normality $[D(62)=0.10 ; P=.20$ for self-esteem; and $D(62)=0.11 ; P=.06$ for noncarrier emotions]. Participants' potential carrier emotions and posttest noncarrier emotions were compared with the use of a paired-samples $t$ test. Hypothesized paths among study variables (self-esteem, fertility distress, potential carrier emotions, coping, and posttest noncarrier emotions; Supplemental Fig. 1) were tested with the use of path analysis with maximum likelihood estimation (MLE). Path analysis was selected because of its ability to analyze multiple regression paths simultaneously. As a prerequisite for using MLE, multivariate normality was evaluated by means of Mardia coefficient and its critical ratio. A critical ratio value of $>1.96$ at the $5 \%$ level of significance was considered to be a violation of the multivariate normality assumption. All study variables met the assumption of multivariate normality.

The final model tested via path analysis examined whether potential carrier emotions mediated the association between self-esteem and fertility distress. Baron and Kenny's (46) four-step approach, followed by calculation of the Sobel test, was used to test the mediational model. Because of the relatively small sample size, testing of the mediational model also included a bootstrapping procedure using 1,000 resamples with a 95\% biascorrected confidence interval (47).

\section{RESULTS}

\section{Sample Description}

A majority of the 62 participants (72.6\%) were white, with 21\% Asian, 3.2\% black, and $3.2 \%$ other races. Average age at first attempt to conceive was 32 years (SD 6.9). All participants had undergone at least one infertility treatment; data on the success of those treatments were not collected. Fertility medication $(96.1 \%)$ and intrauterine insemination (77.8\%) were the most frequent fertility treatments, followed by in vitro fertilization (IVF) (34.5\%) and donor-egg IVF (5.5\%). Table 1 describes the sample in terms of demographics and reproductive health history. Sixty percent had secondary infertility; data were unavailable to determine whether earlier pregnancies were conceived with fertility treatment.

Means, SDs, and correlations of the baseline and follow-up data are presented in Table 2. The sample had higher than average self-esteem compared with normal data from the U.S. (48): $79 \%$ had a self-esteem score above the U.S. median, and $40 \%$ had a self-esteem score higher than 1 SD above the mean. Regarding the potential to be a fragile X carrier, $4.8 \%$ ( $\mathrm{n}$ $=3$ ) had a very favorable response (score 289$), 30.6 \%(\mathrm{n}=19)$ had a favorable response (score 67-88) (44), 53.2\% ( $\mathrm{n}=33)$ were ambivalent (score 45-66), 11.3\% $(\mathrm{n}=7)$ had an unfavorable response (score 23-44), and $0 \%$ had a very unfavorable response (score $\_22$ ). Using norms published by Newton $(21), 19 \%(\mathrm{n}=12)$ of participants experienced low fertility distress, $56 \%(\mathrm{n}=35)$ experienced average fertility distress, and $24 \%(\mathrm{n}=15)$ experienced high fertility distress. Participants had higher CSIC coping scores than married couples who had been diagnosed with infertility from any known or unknown cause $(P<$. 001) (40). Three months after learning they were not a carrier, participants had the following feelings about not being a fragile $\mathrm{X}$ carrier: $62.8 \%(\mathrm{n}=34)$ very favorable, $29.1 \%(\mathrm{n}=16)$ favorable, $9.1 \%(\mathrm{n}=5)$ ambivalent, and $0 \%$ unfavorable or very unfavorable. Participants' emotions after learning that they are not a carrier of a fragile $\mathrm{X}$ premutation (mean 88.62, SD 10.86) were significantly more positive than their pretest emotions toward potentially 
being a carrier (mean 62.29, SD 14.01; $t(61)=-11.815 ; P<.001)$. This contrast bolsters confidence in the validity of the emotion measure in this sample.

Fertility distress was significantly and negatively correlated with self-esteem and potential carrier emotions, and self-esteem was significantly and positively correlated with potential carrier emotions (Table 2). Posttest noncarrier emotions and coping were not correlated with other study variables.

\section{Hypothesis Testing}

The hypothesized model was tested using path analysis. Results (Fig. 1) indicate that selfesteem was a significant, inverse predictor of fertility distress $(b=-18.59 ; \mathrm{SE}=8.70$; critical ratio $=-2.14 ; P=.03)$ and a significant predictor of potential carrier emotions $(b=$ 11.84; $\mathrm{SE}=3.18$; critical ratio $=3.72 ; P \leq 01)$. Potential carrier emotions were also significantly and inversely associated with fertility distress $(b=-0.76 ; \mathrm{SE}=0.32$; critical ratio $=-2.41 ; P=.02)$. Fertility distress was not a significant predictor of coping $(b=0.05$; $\mathrm{SE}=0.03$; critical ratio $=1.71 ; P=.09$ nor of posttest noncarrier emotions, $(b=0.00 ; \mathrm{SE}=$ $0.00 ;=0.17 ; P=.86)$. Similarly, self-esteem $(b=-0.06 ; \mathrm{SE}=0.06 ;$ critical ratio $=-1.0 ; P=$. 32 ), potential carrier emotions ( $b=0.00 ; \mathrm{SE}=0.00$; critical ratio $=0.35 ; P=.73)$, and coping $(b=0.00 ; \mathrm{SE}=0.00 ;$ critical ratio $=0.76 ; P=.45)$ did not predict posttest noncarrier emotions. The tested model exhibited good fit. The chi-square was nonsignificant $\left(X^{2}(2)=\right.$ $2.419 ; P=.298)$. The comparative fit index was 0.98 . For this index, values $>0.95$ are desirable. Finally, the root mean square error of approximation (RMSEA) was 0.0590 (90\% confidence interval $[\mathrm{CI}]=0.00-0.27 ; P_{\mathrm{Close}}=0.35$ ); for this fit index, values $<0.6$ are optimal. The large confidence interval for the RMSEA is most likely attributable to the relatively small sample size.

The final model examined whether potential carrier emotions mediate the association between self-esteem and fertility distress (Fig. 2). Methodologic details are provided in the Supplemental Methods (available online at www.fertstert.org). Self-esteem and potential carrier emotions were correlated $(r=0.43 ; P<.01)$; thus, the first requirement of mediation was met. A series of regression analyses were subsequently performed (see Supplemental Table 1, available online at www.fertstert.org, for unstandardized regression weights and corresponding bootstrapping standard errors). Self-esteem was associated with fertility distress (path c) and with the predicted mediator, potential carrier emotions (path a). Controlling for self-esteem, potential carrier emotions were significantly associated with fertility distress (path b). Finally, when potential carrier emotions was added to the model, the association of self-esteem with fertility distress was reduced significantly (path $c^{\prime}$ ): Sobel test: $Z=2.00 ; P=.02$. However, path $c$ 'remained significant, consistent with partial mediation. The bias-corrected $95 \%$ CIs did not include zero, indicating statistical significance. Self-esteem accounted for $18.5 \%$ of variance in potential carrier emotions. Self-esteem and potential carrier emotions accounted for $22.9 \%$ of variance in fertility distress.

\section{DISCUSSION}

The present study examined levels of and hypothesized associations among self-esteem, emotional reaction to potentially being a fragile $\mathrm{X}$ genetic carrier, fertility distress, and coping. Among this sample of women diagnosed with DOR, almost one-fourth had high fertility distress and $56 \%$ had average levels of fertility distress. These distress scores were similar to earlier reports using the same measure $(23,24)$, demonstrating that the magnitude of fertility distress of women with a DOR diagnosis is similar to that among infertile women in general $(P>$.15). Furthermore, self-esteem in the present sample was high, with $79 \%$ scoring above the U.S. median. 
For women in this study, the introduction of a genetic test (fragile $\mathrm{X}$ in this case) represented new information with the potential for increased distress, because of its possible reproductive implications, or decreased stress, because it offered the possibility of an explanation for the DOR diagnosis. The well fitting Structural Equation Model (SEM) tested here confirmed, as hypothesized, that self-esteem buffered these reactions to potentially being a fragile $\mathrm{X}$ carrier: Higher self-esteem predicted lower fertility distress both directly and indirectly through its association with more favorable emotional reactions to potentially being a fragile $\mathrm{X}$ premutation carrier. In addition, we observed that potential carrier emotional reactions (pretest) were ambivalent or positive for a majority of the sample. This suggests that the potential of having an explanation for one's DOR condition may have been perceived as beneficial by some women, thus balancing the negative perception of what it would be like to be a carrier among infertile women (49). Furthermore, study variables assessed before testing did not predict emotions 3 months later, after women knew of their noncarrier status, indicating that there was no lasting emotional impact of the testing process.

Contrary to our hypothesis, fertility distress was not associated with coping in this sample of women with DOR. This lack of association corroborates a study that used a different measure of coping in a small sample of infertile women (29), but it differs from three other reports with larger samples of infertile women ( $\mathrm{n} 2250)$. Martins et al. (27) and Peterson et al. (23) both reported a statistically significant association between FPI scores and coping (measured with the Copenhagen Multicenter Psychosocial Infertility Questionnaire and the Ways of Coping Questionnaire, respectively), and Lykeridou et al. (25) reported an association between fertility distress and coping (both constructs measured with the Copenhagen Multicenter Psychosocial Infertility Questionnaire). The CSIC (40) used in the present investigation does not measure active-confronting and passive-avoidance coping as do many other coping instruments. Although the CSIC was administered in this population specifically because it was designed for infertile individuals, the underlying definition of coping operationalized by the CSIC appears to vary from other instruments and therefore it may not register associations with infertility distress. Additionally, coping scores had limited variance in this study, which may have constrained our ability to observe associations with this variable. (The variance of coping scores was significantly lower than the variances of other study variables: all $P$ values <.05).

To our knowledge, there is no literature with which to compare our findings on the relationship between self-esteem and emotional reaction to potentially being a carrier of a fragile X premutation. Self-esteem has been associated with fertility stress (50), as measured with a different instrument (32). A construct related to self-esteem, namely resilience, has also been shown to be protective against fertility distress in two recent studies $(28,29)$. The present sample of women diagnosed with DOR had high self-esteem relative to U.S. norms, corroborating past studies comparing self-esteem between infertile and fertile individuals which found either no difference between them (51) or higher scores in infertile women (52). The high self-esteem in the present sample may also reflect education and/or household income greater than the norm, because the states of residence of these women (Virginia, North Carolina, and California) do not mandate insurance coverage for IVF procedures. Our findings suggest that women who present to an infertility clinic with low self-esteem may be at greatest risk for psychologic distress on their quest to achieve a successful pregnancy.

\section{Clinical Implications: Genetic Testing and Fertility Distress}

Infertile women seek fertility assistance because they want to become pregnant, and they are unlikely to have any reason to think their infertility is related to a genetic condition. They often have undergone months or years of unsuccessful infertility treatment and tests and may 
consider the fragile $\mathrm{X}$ testing to be at long last an explanation for their infertility. The diagnosis of DOR is typically accompanied by medical advice to proceed with IVF with a donor egg or to adopt. So these DOR women may have already been engaged in a lengthy coping process that has helped them to adjust to their current situation.

When the present study participants were invited to participate in the underlying fragile $\mathrm{X}$ study, the introduction of a genetic test may have represented new information to them, not only as a new potential explanation for their infertility but also as a new reproduction concern if they were found to be a premutation carrier (unpublished qualitative study). Thus, this genetic test may hold both welcome and unwelcome information: welcome in that an explanation for one's DOR may be better than no explanation at all, and unwelcome because such a diagnosis carries implications for both fertility treatment and general health and wellbeing of both the patient and her offspring.

The decision to have, as opposed to decline, a genetic test has been associated with a variety of factors, such as race/ethnicity (53), risk perception (54), and perceived controllability (54). No earlier research was identified pertinent to fertility distress and the utilization of genetic testing. However, women with a family history of breast or ovarian cancer who chose to have BRCA1/2 testing had higher psychologic distress related to breast cancer (measured with study-specific questions) than relatives who declined that genetic testing (54). Similarly, women who opted to have prenatal screening for fetal abnormalities (serum alpha-fetoprotein) had higher distress levels than women who declined the test (55). Women in our study could participate without learning their test result, although the overwhelming majority chose to learn the results.

Our findings suggest that few women in fertility clinics may respond unfavorably to potentially being a fragile $\mathrm{X}$ premutation carrier, perhaps because they are likely to focus on the welcome aspect of knowing the cause of their DOR condition. However, study results also suggest that among women who respond with negative emotions, fertility distress is likely to be exacerbated. This relationship may extrapolate to other genetic testing offered by fertility clinics. Higher distress is important to consider clinically, because fertility distress has been shown to predict reduced fertility treatment success (56).

\section{Study Limitations and Strengths}

There was no other research using the CSIC coping instrument other than the original publication (40), and this limits our ability to comment on the comparability of study findings with this variable. Other limitations of this work include the relatively modest sample size, which precluded analysis of potential modifiers such as primary versus secondary infertility. However, the sample size was adequate to test the hypothesized model, with at least five to ten subjects per parameter (57). The generalizability of our findings is limited to women seeking medical intervention to enhance fertility, and it may be further limited to women willing to participate in a study and willing to have a genetic test. Regarding strengths, the sample represents a defined infertility cohort with consistent diagnostic criteria. Use of SEM yielded more informative results than data analytic techniques previously used to investigate fertility distress (e.g., analysis of variance, linear regression, correlation) $(22,23,25,28,30)$. Most importantly, this study exhibits the ability to evaluate the impact of a particular genetic test on fertility distress.

\section{Conclusion}

Understanding factors that influence fertility distress is of value to fertility clinic professionals and mental health therapists as they identify women who may need greater support. Clearly our findings underscore the complexity of emotional responses people have 
to infertility. This is one of the first scientifically robust investigations of distress and its predictors among women diagnosed with DOR. Results confirm the hypothesized association of self-esteem and emotional response to the prospect of carrying a genetic premutation with fertility distress among these women. The potential of having an explanation for one's DOR condition may be emotionally beneficial, especially for women with higher self-esteem. Most women in this study had high self-esteem and did not experience strong negative emotions or distress. However, psychologic interventions targeted particularly to DOR women with low self-esteem may reduce distress and potentially improve reaction to genetic test procedures and results.

\section{Supplementary Material}

Refer to Web version on PubMed Central for supplementary material.

\section{Acknowledgments}

The authors thank the clinical research coordinators (Amy Brown, Parchayi Dalal, and Angie Morey) for their recruitment and enrollment efforts, and the lead investigators at the recruitment sites (Drs. Valerie Baker, Christopher Williams, and Steven Young). The authors are grateful also for the participation of the Carolina Conceptions fertility clinic in recruitment efforts.

Supported by the Eunice K. Shriver National Center for Child Health and Human Development, National Institutes of Health (grants HD052768, HD057485, and HD068440 to L.M.P.). The content is solely the responsibility of the authors and does not necessarily represent the official views of the National Institutes of Health.

\section{REFERENCES}

1. Boivin J, Bunting L, Collins JA, Nygren KG. International estimates of infertility prevalence and treatment-seeking: potential need and demand for infertility medical care. Hum Reprod. 2007; 22:1506-12. [PubMed: 17376819]

2. Sharara FI, Scott JRT, Seifer DB. The detection of diminished ovarian reserve in infertile women. Am J Obstet Gynecol. 1998; 179:804-12. [PubMed: 9757994]

3. Levi AJ, Raynault MF, Bergh PA, Drews MR, Miller BT, Scott RT Jr. Reproductive outcome in patients with diminished ovarian reserve. Fertil Steril. 2001; 76:666-9. [PubMed: 11591396]

4. Scott RT Jr, Hofmann GE. Prognostic assessment of ovarian reserve. Fertil Steril. 1995; 63:1-11. [PubMed: 7805895]

5. Friese C, Becker G, Nachtigall RD. Rethinking the biological clock: eleventh-hour moms, miracle moms and meanings of age-related infertility. Social Sci Med. 2006; 63:1550-60.

6. ACOG Committee of Genetics. Carrier screening for fragile X syndrome. Obstet Gynecol. 2010; 116:1008-10. [PubMed: 20859177]

7. Sherman SL. Premature ovarian failure in the fragile X syndrome. Am J Med Genet. 2000; 97:18994. [PubMed: 11449487]

8. Karimov CB, Moragianni VA, Cronister A, Srouji S, Petrozza J, Racowsky C, et al. Increased frequency of occult fragile $\mathrm{X}$-associated primary ovarian insufficiency in infertile women with evidence of impaired ovarian function. Hum Reprod. 2011; 26:2077-83. [PubMed: 21646280]

9. Pastore LM, Young SL, Baker VM, Karns LB, Williams CD, Silverman LM. Elevated prevalence of 35-44 FMR1 trinucleotide repeats in women with diminished ovarian reserve. Reprod Sci. 2012; 19:1226-31. [PubMed: 22581803]

10. Streuli I, Fraisse T, Ibecheole V, Moix I, Morris MA, de Ziegler D. Intermediate and premutation FMR1 alleles in women with occult primary ovarian insufficiency. Fertil Steril. 2009; 92:464-70. [PubMed: 18973899]

11. Gleicher N, Weghofer A, Barad DH. A pilot study of premature ovarian senescence: I. Correlation of triple CGG repeats on the FMR1 gene to ovarian reserve parameters FSH and anti-müllerian hormone. Fertil Steril. 2009; 91:1700-6. [PubMed: 18384775] 
12. Ulrich M, Weatherall A. Motherhood and infertility: viewing motherhood through the lens of infertility. Feminism Psychol. 2000; 10:323-6.

13. Glover L, McLellan A, Weaver SM. What does having a fertility problem mean to couples? J Reprod Infant Psychol. 2009; 27:401-18.

14. Martin-Matthews, A.; Matthews, R. Living in time: multiple timetables in couples' experiences of infertility and its treatment. In: Daly, K., editor. Minding in time in family experience: emerging perspectives and issues. JAI and Elsevier Science; New York: 2001.

15. Williams ME. Toward greater understanding of the psychological effects of infertility on women. Psychother Priv Practice. 1997; 16:7-26.

16. Gonzalez LO. Infertility as a transformational process: a framework for psychotherapeutic support of infertile women. Issues Ment Health Nurs. 2000; 21:619-33. [PubMed: 11271137]

17. Hinton L, Kurinczuk JJ, Ziebland S. Infertility; isolation and the Internet: a qualitative interview study. Patient Educ Counsel. 2010; 81:436-41.

18. McCarthy MP. Women's lived experience of infertility after unsuccessful medical intervention. J Midwifery Women's Health. 2008; 53:319-24. [PubMed: 18586184]

19. Dunkel-Schetter, C.; Lobel, M. Psychological reactions to infertility. In: Stanton, A.; DunkelSchetter, C., editors. Infertility: perspectives from stress and coping research. Plenum Press; New York: 1991. p. 27-57.

20. Groff AA, Covington SN, Halverson LR, Fitzgerald OR, Vanderhoof V, Calis K, et al. Assessing the emotional needs of women with spontaneous premature ovarian failure. Fertil Steril. 2005; 83:1734-41. [PubMed: 15950644]

21. Newton CR, Sherrard W, Glavac I. The fertility problem inventory: measuring perceived infertility-related stress. Fertil Steril. 1999; 72:54-62. [PubMed: 10428148]

22. Peterson BD, Newton CR, Rosen KH. Examining congruence between partners' perceived infertility-related stress and its relationship to marital adjustment and depression in infertile couples. Fam Process. 2003; 42:59-70. [PubMed: 12698599]

23. Peterson BD, Newton CR, Rosen KH, Skaggs GE. Gender differences in how men and women who are referred for IVF cope with infertility stress. Hum Reprod. 2006; 21:2443-9. [PubMed: 16675482]

24. Slade P, O'Neill C, Simpson AJ, Lashen H. The relationship between perceived stigma, disclosure patterns, support and distress in new attendees at an infertility clinic. Hum Reprod. 2007; 22:2309-17. [PubMed: 17580298]

25. Lykeridou K, Gourounti K, Sarantaki A, Loutradis D, Vaslamatzis G, Deltsidou A. Occupational social class, coping responses and infertility-related stress of women undergoing infertility treatment. J Clin Nurs. 2011; 20:1971-80. [PubMed: 21564361]

26. van den Broeck U, Hooghe T, Enzlin P, Demyttenaere K. Predictors of psychological distress in patients starting IVF treatment: infertility-specific versus general psychological characteristics. Hum Reprod. 2010; 25:1471-80. [PubMed: 20338959]

27. Martins MV, Peterson BD, Almeida VM, Costa ME. Direct and indirect effects of perceived social support on women's infertility-related stress. Hum Reprod. 2011; 26:2113-21. [PubMed: 21596709]

28. Herrmann D, Scherg H, Verres R, von Hagens C, Strowitzki T, Wischmann T. Resilience in infertile couples acts as a protective factor against infertility-specific distress and impaired quality of life. J Assist Reprod Genet. 2011; 28:1111-7. [PubMed: 21901362]

29. Sexton MB, Byrd MR, von Kluge S. Measuring resilience in women experiencing infertility using the CD-RISC: Examining infertility-related stress, general distress, and coping styles. J Psychiatr Res. 2010; 44:236-41. [PubMed: 19665730]

30. Gourounti K, Anagnostopoulos F, Vaslamatzis G. Psychometric properties and factor structure of the Fertility Problem Inventory in a sample of infertile women undergoing fertility treatment. Midwifery. 2011; 27:660-7. [PubMed: 20359796]

31. Slade PD, Dewey ME, Newton T, Brodie DA. Development and preliminary validation of the Body Satisfaction Scale (BSS). Psychol Health. 1990; 4:213-20.

32. Abbey A, Halman LJ, Andrews FM. Psychosocial, treatment, and demographic predictors of the stress associated with infertility. Fertil Steril. 1992; 57:122-8. [PubMed: 1730305] 
33. Domar AD, Clapp D, Slawsby EA, Dusek J, Kessel B, Freizinger M. Impact of group psychological interventions on pregnancy rates in infertile women. Fertil Steril. 2000; 73:805-11. [PubMed: 10731544]

34. Lancastle D, Boivin J. Dispositional optimism, trait anxiety, and coping: unique or shared effects on biological response to fertility treatment? Health Psychol. 2005; 24:171-8. [PubMed: 15755231]

35. Brown J. High self-esteem buffers negative feedback: once more with feeling. Cognition. 2010; 24:1389-404.

36. Holahan C, Moos R. Life stressors, resistance factors, and improved psychological functioning: an extension of the stress resistance paradigm. J Pers Soc Psychol. 1990; 58:909-17. [PubMed: 2348376]

37. Lazarus, R.; Folkman, S. Stress, appraisal, and coping. Springer; New York: 1984.

38. Rosenberg, M. Conceiving the self. Krieger; Malabar, FL: 1986.

39. Rosenberg, M. Society and the adolescent self-image. Princeton University Press; Princeton, NJ: 1965.

40. Lee TY, Sun GH, Chao SC, Chen CC. Development of the Coping Scale for Infertile Couples. Arch Androl. 2000; 45:149-54. [PubMed: 11111863]

41. Cohen S, Kamarck T, Mermelstein R. A global measure of perceived stress. J Health Social Behav. 1983; 24:385-96.

42. Bernstein J, Potts N, Mattox JH. Assessment of psychological dysfunction associated with infertility. J Obstet Gynecol Neonatal Nurs. 1985; 14:63s-6s.

43. Jalowiec A, Murphy SP, Powers MJ. Psychometric assessment of the Jalowiec Coping Scale. Nurs Res. 1984; 33:157-61. [PubMed: 6563533]

44. Wooldridge EQ, Murray RFJ. The Health Orientation Scale: a measure of feelings about sickle cell trait. Soc Biol. 1988; 35:126-36.

45. Tabachnick, BG.; Fidell, LS. Using multivariate statistics. 5th ed. Allyn and Bacon; Boston: 2007.

46. Baron RM, Kenny DA. The moderator-mediator variable distinction in social psychological research: conceptual, strategic and statistical considerations. J Pers Soc Psychol. 1986; 51:117382. [PubMed: 3806354]

47. Shrout PE, Bolger N. Mediation in experimental and nonexperimental studies: new procedures and recommendations. Psychol Methods. 2002; 7:422-45. [PubMed: 12530702]

48. Sinclair SJ, Blais MA, Gansler DA, Sandberg E, Bistis K, LoCicero A. Psychometric properties of the Rosenberg Self-Esteem Scale: overall and across demographic groups living within the United States. Eval Health Prof. 2010; 33:56-80. [PubMed: 20164106]

49. Pastore LM, Morris WL, Karns LB, Pastore LM, Morris WL, Karns LB. Emotional reaction to fragile X premutation carrier tests among infertile women. J Genetic Counsel. 2008; 17:84-91.

50. Schneider MG, Forthofer MS. Associations of psychosocial factors with the stress of infertility treatment. Health Soc Work. 2005; 30:183-91. [PubMed: 16190294]

51. Adler J, Boxley R. The psychological reactions to infertility: sex roles and coping styles. Sex Roles. 1985; 12:271-9.

52. Dennerstein L, Morse C. Psychological issues in IVF. Clinics Obstet Gynaecol. 1985; 12:835-46.

53. Skinner D, Choudhury S, Sideris J, Guarda S, Buansi A, Roche M, et al. Parents' decisions to screen newborns for FMR1 gene expansions in a pilot research project. Pediatrics. 2011; 127:e1455-63. [PubMed: 21624881]

54. Katapodi M, Northouse L, Pierce P, Milliron K, Liu G, Merajver S. Differences between women who pursued genetic testing for hereditary breast and ovarian cancer and their at-risk relatives who did not. Oncol Nurs Forum. 2011; 38:572-81. [PubMed: 21875844]

55. Lobel M, Dias L, Meyer B. Distress associated with prenatal screening for fetal abnormality. J Behav Med. 2005; 28:65-76. [PubMed: 15887877]

56. Boivin J, Schmidt L. Infertility-related stress in men and women predicts treatment outcome 1 year later. Fertil Steril. 2005; 83:1745-52. [PubMed: 15950646]

57. Muthén L, Muthén B. How to use a Monte Carlo study to decide on sample size and determine power. Struct Equ Modeling. 2002; 9:599-620. 


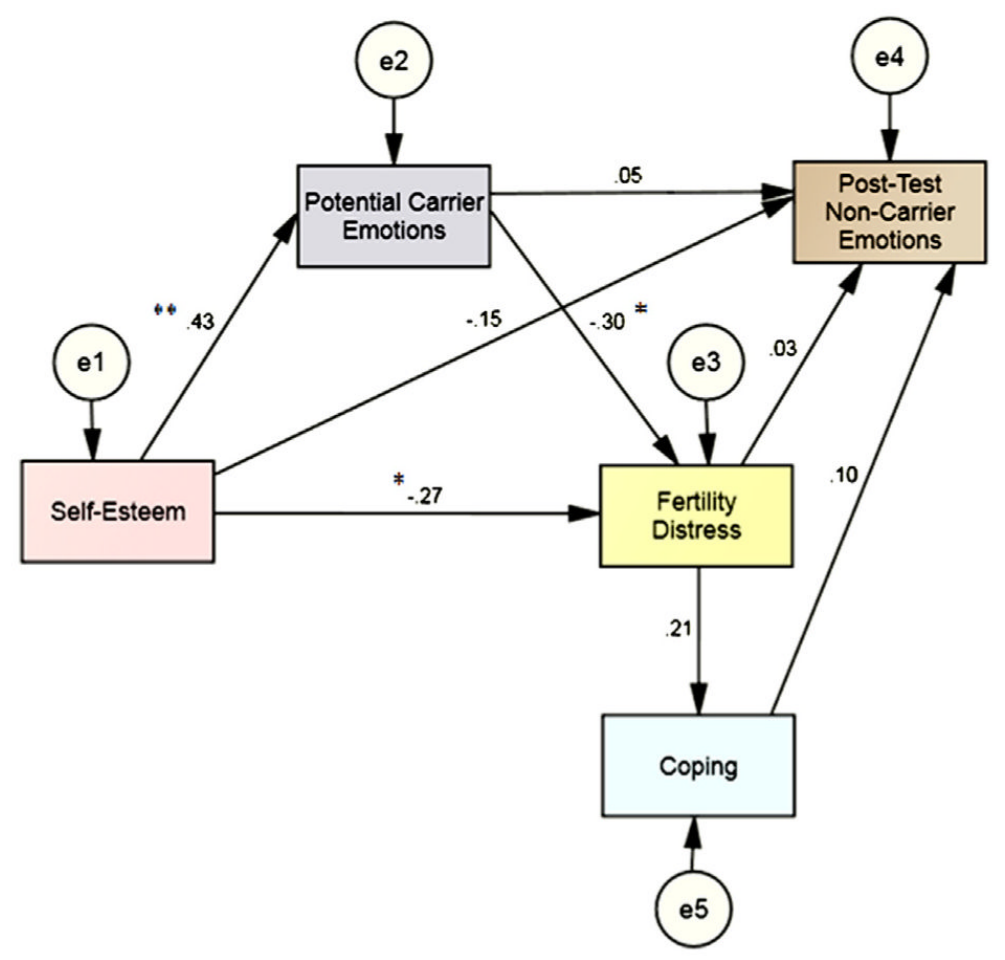

FIGURE 1.

The path model with standardized regression weights. $(* P<.05 ; * * P<.001)$. Cizmeli. Fertility distress in women with DOR. Fertil Steril 2013. 


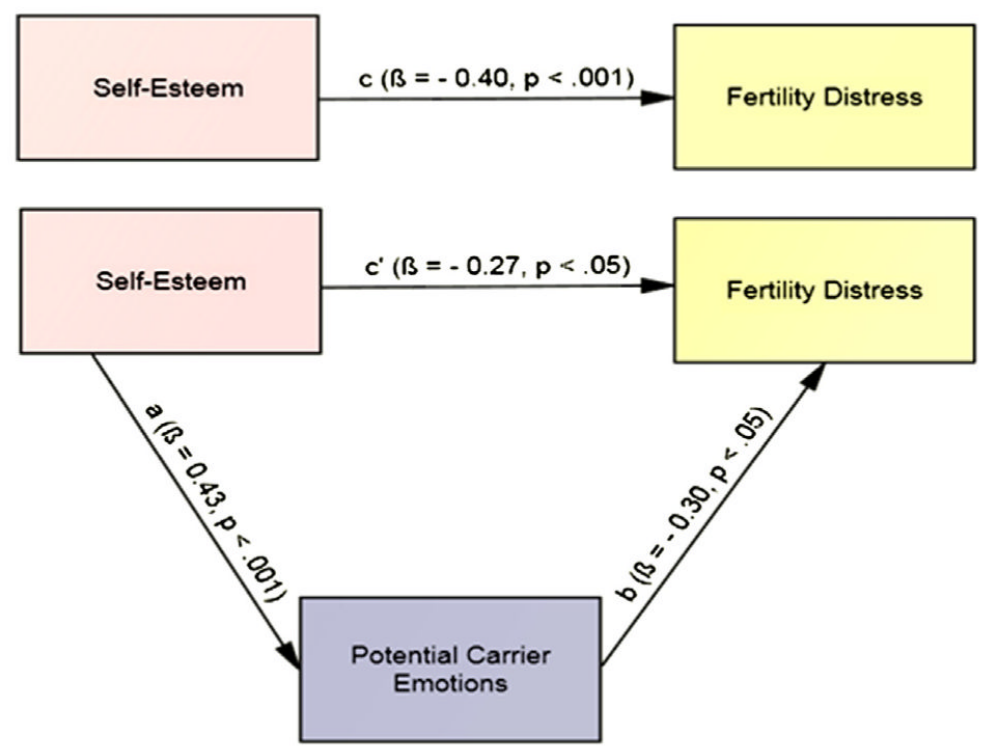

FIGURE 2.

Model hypothesizing potential carrier emotions as a mediator of the association between self-esteem and fertility distress with standard regression coefficients.

Cizmeli. Fertility distress in women with DOR. Fertil Steril 2013. 


\section{TABLE 1}

Participant demographics and reproductive health history characteristics, $\%$ (n) or mean \pm SD.

\begin{tabular}{lc}
\hline Characteristic & \\
Age at study participation (y) & $38.2 \pm 3.8$ \\
Age at DOR diagnosis (y) & $37.0 \pm 3.8$ \\
Race & \\
White & $72.6 \%(45)$ \\
Black & $3.2 \%(2)$ \\
Asian & $21.0 \%(13)$ \\
Other & $3.2 \%(2)$ \\
Reproductive health history & \\
Age at first menses (y) & $12.60 \pm 1.37$ \\
Nulligravid & $40.3 \%(25)$ \\
Parity & \\
0 & $77.8 \%(42)$ \\
1 & $18.5 \%(10)$ \\
2 & $3.7 \%(2)$ \\
\hline
\end{tabular}

Cizmeli. Fertility distress in women with DOR. Fertil Steril 2013. 
TABLE 2

Means, standard deviations, and correlations for study variables.

\begin{tabular}{|c|c|c|c|c|c|c|c|}
\hline Variable & Mean \pm SD & Range & Self-esteem & $\begin{array}{c}\text { Potential carrier } \\
\text { emotions }\end{array}$ & $\begin{array}{c}\text { Posttest noncarrier } \\
\text { emotions }\end{array}$ & $\begin{array}{l}\text { Fertility } \\
\text { distress }\end{array}$ & Coping \\
\hline Self-esteem & $78.7 \pm 12.61$ & $44-90$ & - & $0.43^{*}$ & -0.13 & $-0.40^{*}$ & 0.09 \\
\hline $\begin{array}{l}\text { Potential carrier } \\
\text { emotions }\end{array}$ & $62.3 \pm 14.01$ & $26-95$ & & - & -0.03 & $-0.42^{*}$ & -0.06 \\
\hline $\begin{array}{l}\text { Posttest noncarrier } \\
\text { emotions }\end{array}$ & $88.6 \pm 10.86$ & $59-99$ & & & - & 0.09 & 0.09 \\
\hline Fertility distress & $138.4 \pm 35.58$ & $75-232$ & & & & - & 0.21 \\
\hline Coping & $46.5 \pm 8.41$ & $25-67$ & & & & & - \\
\hline
\end{tabular}

Cizmeli. Fertility distress in women with DOR. Fertil Steril 2013. 